\title{
Changes of Micro- and Nanoscopic Morphology of Various Bioresources by Different Milling Systems ${ }^{1}$
}

\author{
Jae-Hyuk Jang ${ }^{2,3} \cdot$ Seung-Hwan Lee $^{3} \cdot$ Min Lee $^{2} \cdot$ Sang-Min Lee ${ }^{2} \cdot$ Nam-Hun Kim (D) ${ }^{3, \dagger}$
}

\begin{abstract}
This study was carried out to investigate the changes in micro- and nanoscopic morphology of cellulose nanofibrils (CNFs) from various bioresources by investigating various mechanical milling systems. Mechanical milling in herbaceous bioresources was more effective than in woody bioresources, demonstrating lower energy consumption and finer morphology. The milling time to reach nanoscopic size was longer in woody bioresources than in herbaceous bioresources. Furthermore, at the same level of wet disk milling time, CNFs from herbaceous bioresources showed more slender morphology than those from woody bioresources. Tensile properties of nanopaper prepared from CNFs of herbaceous bioresources were higher than those of woody bioresources. The highest tensile strength was found to be $77.4 \mathrm{MPa}$ in the nanopaper from Evening prim rose.
\end{abstract}

Keywords : nanocellulose, cellulose nanofibril, microfibrillated cellulose, lignocellulose nanofibril, nanopaper

\section{INTRODUCTION}

Cellulose is the most abundant natural polymer on earth, and its utilization has many environmental benefits. Cellulose microfibrils are bundles of stretched cellulose chain molecules, and are the smallest structural units of lignocellulosic bioresources. They exist in nature as nano-structured materials, called cellulose nanofibrils (CNFs). CNFs can be produced from any kind of plant cell walls by chemical and mechanical methods, or by a combination of both chemical and mechanical methods (Eichhorn et al., 2010; Kalia et al., 2011; Lavoine et al., 2012; Siró and Plackett, 2010). Conventional mechanical treatments for $\mathrm{CNF}$ production include cryocrushing, ultrasonication, disk-milling, high-pressure homogenizing, etc. (Chakraborty et al., 2005; Jang et al., 2013; Kondo, 2005; Taniguchi and Okamura, 1998; Yano et al., 2005). The morphological properties of the resulting products are dependent upon the mechanical treatments applied and the origin of bioresources.

It is important to be aware that the kind of lignocellulosic biomass can vary significantly

1 Date Received September 4, 2017, Date Accepted October 13, 2017

2 Department of Forest Products, National Institute of Forest Science, Seoul 02455, Republic of Korea

3 College of Forest and Environmental Sciences, Kangwon National University, Chuncheon 24341, Republic of Korea

† Corresponding author: Nam-Hun Kim (e-mail: kimnh@kangwon.ac.kr, ORCID: 0000-0002-4416-0554) 
Table 1. Samples information

\begin{tabular}{cccccc}
\hline Bioresources & Common name & Scientific name & $\begin{array}{c}\text { Age } \\
(\mathrm{yrs})\end{array}$ & $\begin{array}{c}\text { Density }^{*} \\
\left(\mathrm{~g} / \mathrm{cm}^{3}\right)\end{array}$ & Location \\
\hline \hline Woody & Red pine & Pinus densiflora & 48 & 0.47 & Chuncheon, South Korea \\
bioresources & Korean white pine & Pinus koraiensis & 29 & 0.45 & Chuncheon, South Korea \\
& Japanese poplar & Populus maximowiczii & 34 & 0.56 & Samcheok, South Korea \\
& Willows & Salix pseudolasiogyne & 31 & 0.58 & Chuncheon, South Korea \\
& Bigcatkin willow & Salix gracilistyla & 1 & 0.15 & Chuncheon, South Korea \\
\hline \multirow{2}{*}{$\begin{array}{c}\text { Herbaceous } \\
\text { bioresources }\end{array}$} & Kenaf & Hibiscus cannabinus & 1 & 0.18 & Buan, South Korea \\
& Evening prim rose & Oenothera odorata & 1 & 0.11 & Chuncheon, South Korea \\
\hline \multirow{2}{*}{ Air- } & Corn stover & Zea mays & 1 & 0.16 & Chuncheon, South Korea \\
\hline
\end{tabular}

${ }^{*}$ Air-dried density

among softwoods, hardwoods, and herbaceous resources. As such, it can be affected a significant bearing on the mechanical fibrillation process as well as the final product. The Populus and Salix genus are major fast-growing species, which may have great potential for $\mathrm{CNF}$ production, in terms of economic feasibility. This is due to their adaptability and management of raw material supply. Red pines and Korean white pines are major planted softwood species in Korea. Herbaceous plant materials are also an important source for $\mathrm{CNF}$ production. Kenaf and evening prim rose are fast-growing in temperate and sub-tropical areas (Jonoobi et al., 2009). Corn stover is readily available as this agricultural crop resides in billions of tonnes throughout the world. As these herbaceous resources are abundant, inexpensive, and readily available, these sources may benefit for CNF production. Generally, woody bioresorces have strong recalcitrant properties, resulting in difficulty to produce $\mathrm{CNF}$. CNF in herbaceous bioreources has been known to be more easily separated, compared to woody bio- reources (Alia et al., 2013).

The objective of this study is to investigate the micro- and nanoscopic morphological changes of eight different bioresources by different milling systems. Red pine, Korean white pine, Japanese poplar, and Willows were used as woody sources. Kenaf, evening prim rose and corn stover were used as herbaceous sources. In this study, power consumption during milling, filtration time, and tensile properties of nanopaper were also compared against different raw sources and milling systems.

\section{MATERIALS and METHODS}

\subsection{Materials}

Five woody and three herbaceous bioresources were selected as raw materials. Detailed information of these samples is given in Table 1.

\subsection{Mechanical Grinding}

The oven-dried bioresources were first passed 
through the nine mesh screens (mesh opening size $2.0 \mathrm{~mm}$ ) using a cutter-mill (SM 100, Retsch Co. Ltd., Germany). The obtained particles were subjected to a second grinding, passing through the 32 mesh screen (mesh opening size $0.5 \mathrm{~mm}$ ) using a continuous grinder (KF-20, Korea Medi Co. Ltd., Korea). Ten operation cycles were repeated in each grinding step. The obtained pulverized products were diluted into $2 \%$ water suspension and subjected to wet disk-milling (WDM) (Supermasscolloider MKCA6-2, Masuko Sangyo, Japan). The rotational speed was set at $1800 \mathrm{rpm}$, and the operation was repeated five times. The clearance between the two disks was reduced up to 20 $\mu \mathrm{m}$ from the zero position; where the disks begin to rub. The grinding time $(\mathrm{min} / \mathrm{g})$ was recorded based on the initial material weight. The energy consumption of each operation was calculated using the voltage, current, and operation time.

\subsection{Morphological Characteristics of the Ground Products}

A measuring microscope (MM-40, Nikon Co. Ltd., Japan) was used to observe the morphology of the first and second ground powders. The nanoscopic morphological characteristics were observed using a field emission scanning electron microscope (FE-SEM) (S-4800, Hitachi Co., Ltd., Japan). For the FE-SEM sample preparation, the fibrillated products were diluted to a 0.001 wt $\%$ suspension and then vacuum-filtered. The obtained product was im- mersed in ethanol for $30 \mathrm{~min}$ and transferred into $t$-butyl alcohol for $2 \mathrm{~h}$, followed by freeze-drying for $24 \mathrm{~h}$. For SEM observations, the samples were coated with a 1 nm-thick layer of osmium by using an osmium plasma coater (NEOC-AN, Meiwa Fosis, Japan).

\subsection{Preparation and Characterization of Nanopaper}

The fibrillated product fabricated using wet disk milling (WDM) was diluted to a $0.5 \mathrm{wt} \%$ suspension $(128 \mathrm{~m} \ell)$ and stirred for $10 \mathrm{~min}$, followed by ultrasonication for $30 \mathrm{~s}$ to ensure well-dispersed fibrillated products. The nanopapers were prepared by vacuum filtration on a polytetrafluoroethylene membrane filter (pore size, $0.2 \mu \mathrm{m})$. The filtration time was measured at this stage, as a criterion determining the degree of fibrillation. The wet-sheet was hot-pressed between two silicone-coated sheets of filter paper at $105^{\circ} \mathrm{C}$ for $30 \mathrm{sec}$ at $5 \mathrm{MPa}$ and subsequently for $60 \mathrm{sec}$ at $15 \mathrm{MPa}$. The pressed sheets were further vacuum-dried at $40^{\circ} \mathrm{C}$ for $24 \mathrm{~h}$ and kept for more than 1 day at a temperature of $23{ }^{\circ} \mathrm{C}$ and $50 \%$ relative humidity prior to conducting the tensile test. Three dog-bone samples $(5 \times 0.4 \times 50 \mathrm{~mm})$ were cut from the nanopapers, and the tensile test was conducted using a Shimadzu Autograph (AG-1, $5 \mathrm{kN}$ load cell, Shimadzu Ltd, Japan), with a cross head speed of $5 \mathrm{~mm} / \mathrm{min}$, according to JIS K7127. 


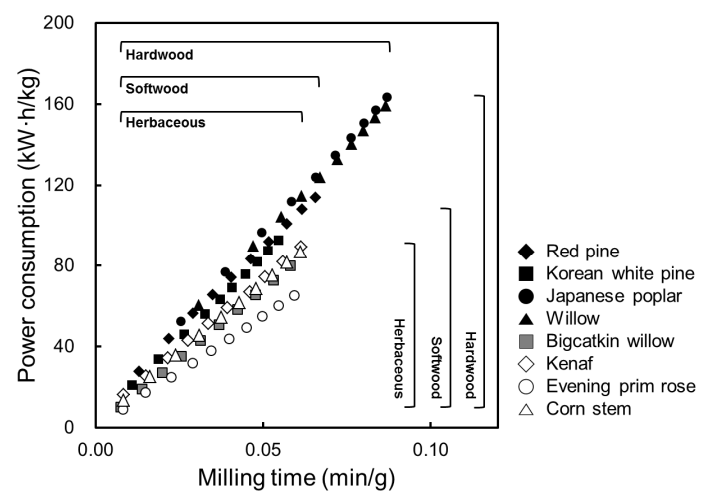

Fig. 1. Power consumption of woody and herbaceous bioresources during second grinding using continuous grinder.

\section{RESULTS and DISCUSSION}

\subsection{Power Consumption during Continuous grinding}

Fig. 1 shows the power consumption of woody and herbaceous bioresources during the second grinding, which was calculated from the voltage, current, and operation time during grinding. In all the cases, power consumption linearly increased with increasing grinding time. At the same of grinding time $(0.05 \mathrm{~min} / \mathrm{g})$, hard-, softwood and herbaceous bioresources consumed approximately 100, 90, and $70 \mathrm{~kW}$ $\mathrm{h} / \mathrm{kg}$ of energy respectively. Evening prim rose consumed significantly lower energy $(60 \mathrm{~kW}$ • $\mathrm{h} / \mathrm{kg}$ ) than other bioresources. In general, woody bioresources have much harder structures than herbaceous bioresources; hardwood is harder than softwood. The difference in energy consumption during grinding may mainly be due to different density and porosity in bioresources. Exceptionally, bigcatkin willow consumed similar energy with herbaceous bioresources, it might be because of their low density $\left(0.15 \mathrm{~g} / \mathrm{cm}^{3}\right)$.

\subsection{Morphology Changes by Three Different Milling System}

Figs. 2 and 3 show morphology changes of woody and herbaceous bioresources by different milling systems such as cutter-milling, continuous grinding, and WDM. Particles obtained by cutter-mill demonstrated more than $1 \mathrm{~mm}$ length and approximately $500 \mu \mathrm{m}$ diameter in both woody and herbaceous bioresources. There was no significant difference between woody and herbaceous bioresources in the cutter-milling system. However, powders obtained by continuous grinding showed a difference in morphology in woody and herbaceous bioresources. The powder from herbaceous sources appeared to have more fiber-like morphology than woody sources.

The average diameter and length changes of the powders, obtained by continuous grinding, is shown in Fig. 4. With increasing grinding time, the diameter and length of the powders decreased. In particular, compared to woody bioresources, dimensions of powders from herbaceous bioresources drastically decreased. In the case of woody bioresources, the dimensions decreased and subsequently leveled off at approximately $0.04 \mathrm{~min} / \mathrm{g}$ of grinding time. For more than $0.04 \mathrm{~min} / \mathrm{g}$ of grinding time, the average diameter and length ranged from 102-170 $\mu \mathrm{m}$ and 275-372 $\mu \mathrm{m}$, in woody bioresources, respectively. However, herbaceous bioresources 


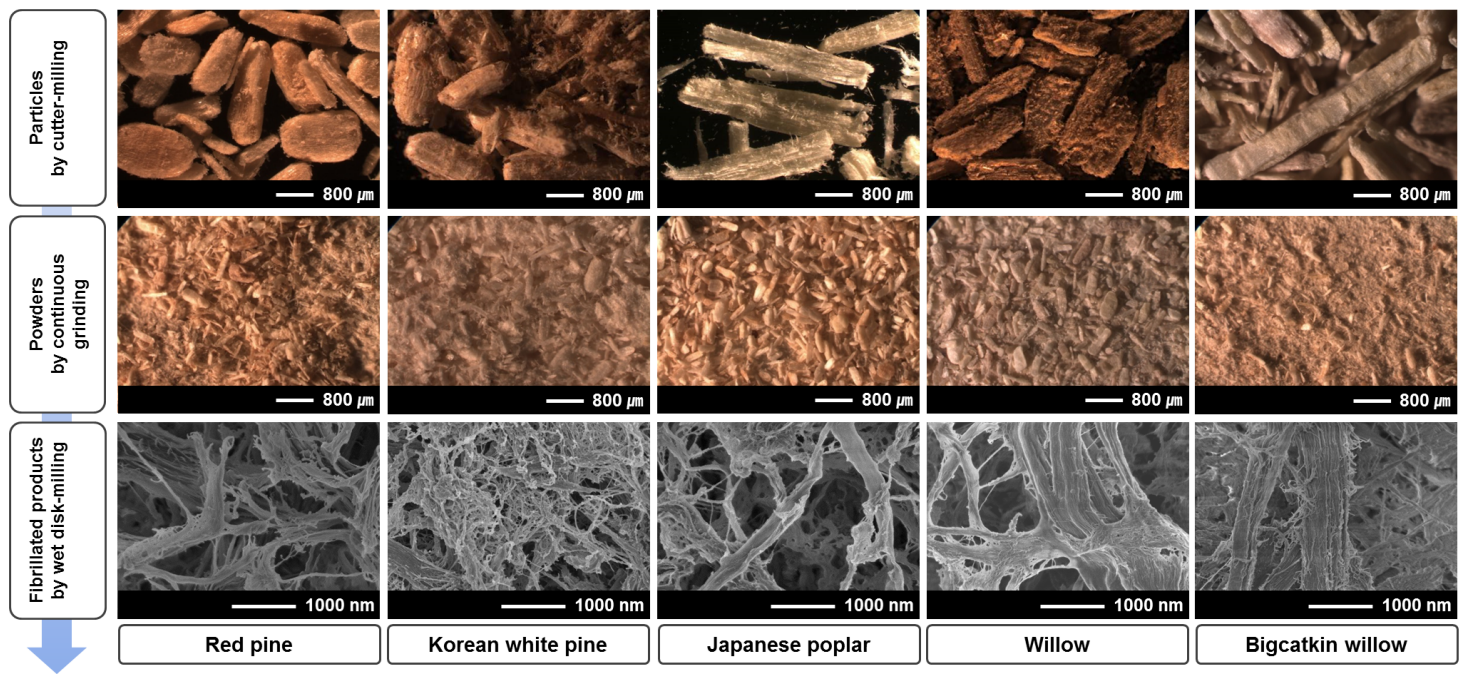

Fig. 2. Morphology changes of woody bioresources by cutter-milling, continuous grinding, and WDM.

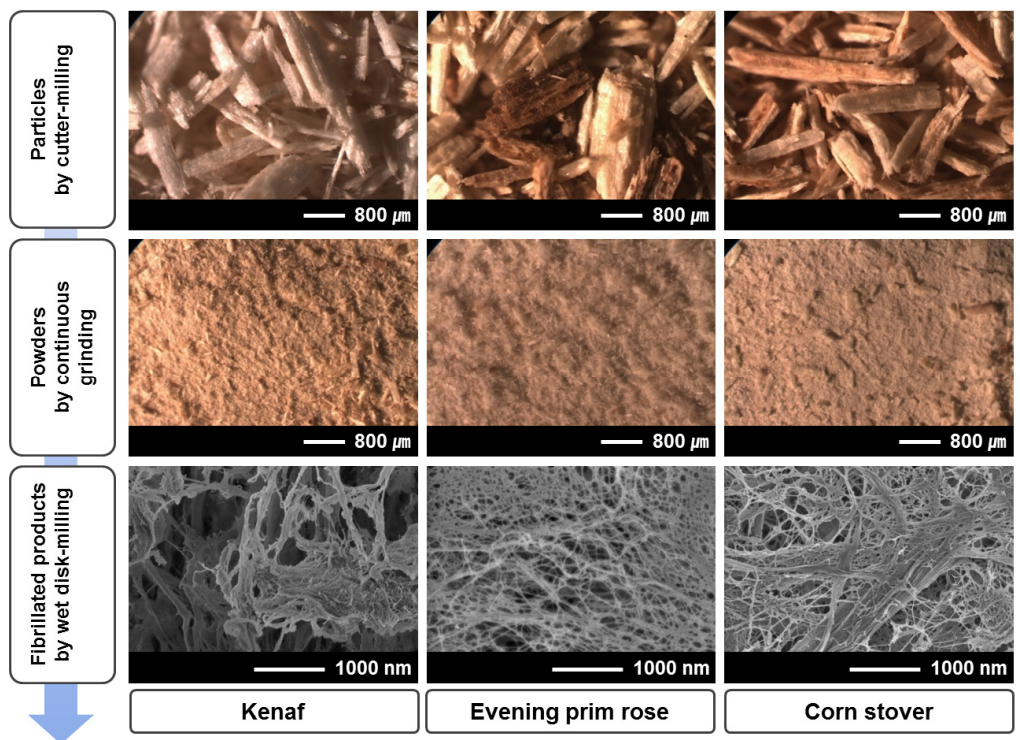

Fig. 3. Morphology changes of herbaceous bioresources by cutter-milling, continuous grinding, and WDM.

showed the average diameter and length ranged from 22-71 $\mu \mathrm{m}$ and 79-254 $\mu \mathrm{m}$, respectively. To attain the minimum size of the powder, the grinding took a longer amount of time in woody bioresources than in herbaceous bioresources. Moreover, hardwoods took a longer time than softwoods. Finally, fibrillated products by WDM showed distinctly different morphology compared to those by two former milling systems, in both resources, as shown in 

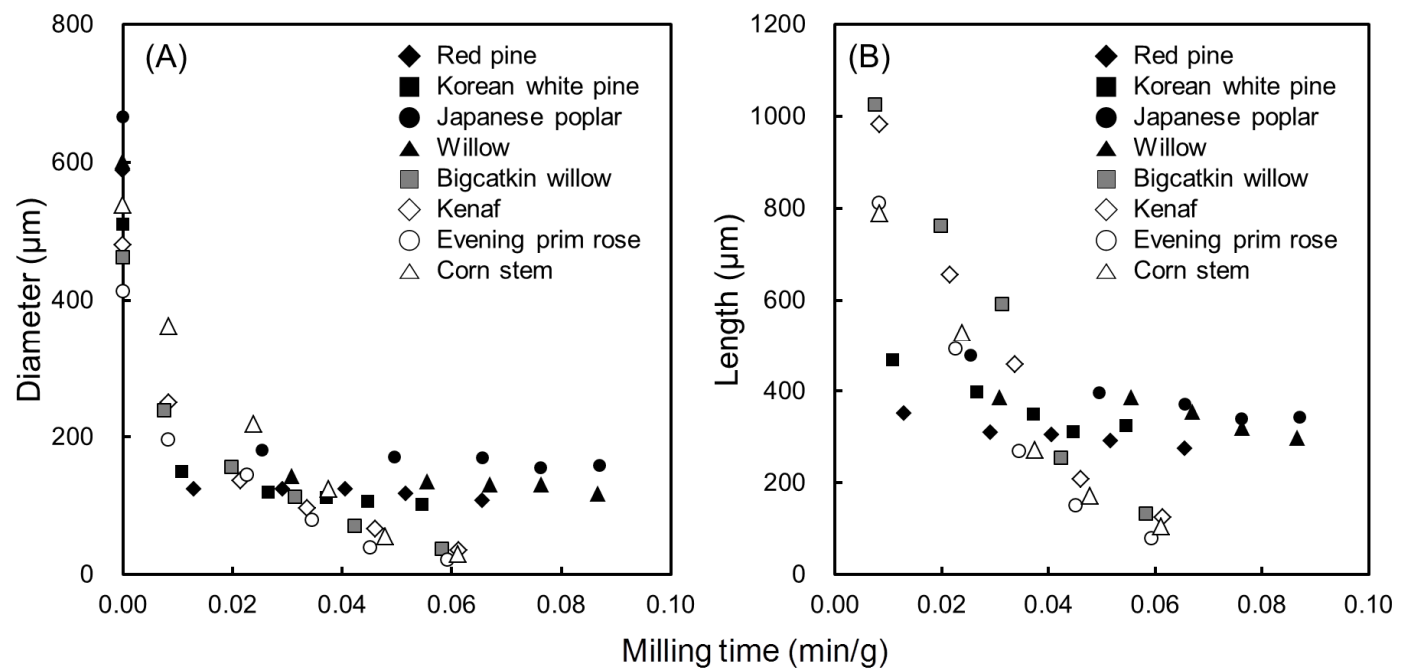

Fig. 4. Average diameter (A) and length (B) changes of ground powders from various bioresources during continuous grinding.

Figs. 2 and 3. Finely fibrillated products seem to be general microfibrillated cellulose (MFC) with long aspect ratios at nanoscale, despite hemicellulose and lignin not being removed. Fibrillated products from herbaceous bioresources showed finer morphologies than woody bioresources: the morphology was finer in softwoods than in hardwoods. Stelte and Sanadi (2009) prepared cellulose nanofibers from two commercial hard- and softwood pulps using high-pressure homogenization. They reported that the softwood fibers lost their structure almost completely after 25 passes of high-pressure homogenization, resulting in aggregates of small fibers, whereas hardwood fibers remained mostly intact after 75 passes. In general, softwood has a relatively simple structure with $90-95 \%$ tracheids, which are long and slender cells. However, hardwood has varied and complex constituent cells with vessel and libriform fibers playing a strengthening role. Furthermore, hardwood has thicker cell walls and smaller lumina than softwood and herbaceous bioresources (Fengel and Wegener, 1983). These different properties in hard- and softwoods may have an effect on fibrillation efficiency. Alila et al. (2013) reported that five non-woody herbaceous bioresources such as hemp, flax, sisal, abaca, and jute have fibers with over $50 \mu \mathrm{m}$ diameter, which are formed of bundles of elementary fibers. However, the pre-treatment and mechanical grinding process ensures optimal separation of the cellulose fibers.

\subsection{Characteristics of Microfibrillated Products by WDM}

Table 2 summarizes WDM time and power consumption during WDM, as well as filtration 
Table 2. Wet disk-milling time, power consumption, filtration time, and average diameter of microfibrillated products

\begin{tabular}{ccccc}
\hline Bioresources & $\begin{array}{c}\text { Wet disk-milling } \\
\text { time }(\mathrm{min} / \mathrm{g})\end{array}$ & $\begin{array}{c}\text { Power } \\
\text { consumption } \\
(\mathrm{kW} \cdot \mathrm{h} / \mathrm{kg})\end{array}$ & $\begin{array}{c}\text { Filtration time } \\
(\mathrm{min})\end{array}$ & $\begin{array}{c}\text { Average } \\
\text { diameter }(\mathrm{nm})\end{array}$ \\
\hline \hline Red pine & 2.35 & 298 & $23.7 \pm 2.2$ & $94 \pm 11$ \\
Japanese poplar & 3.30 & 300 & $35.8 \pm 4.1$ & $102 \pm 24$ \\
Kenaf & 2.23 & 248 & $55.2 \pm 1.8$ & $60 \pm 9$ \\
Evening prim rose & 1.80 & 212 & $74.5 \pm 3.0$ & $21 \pm 4$ \\
\hline
\end{tabular}

Table 3. Tensile properties of the nanopaper made from microfibrillated products

\begin{tabular}{ccccc}
\hline Bioresources & $\begin{array}{c}\text { Wet disk-milling } \\
\text { time }(\mathrm{min} / \mathrm{g})\end{array}$ & $\begin{array}{c}\text { Tensile strength } \\
(\mathrm{MPa})\end{array}$ & $\begin{array}{c}\text { Elastic modulus } \\
(\mathrm{GPa})\end{array}$ & $\begin{array}{c}\text { Elongation at break } \\
(\%)\end{array}$ \\
\hline \hline Red pine & 2.35 & $58.4 \pm 8.1$ & $19.2 \pm 1.8$ & $0.39 \pm 0.09$ \\
Japanese poplar & 3.30 & $61.3 \pm 4.8$ & $17.0 \pm 1.2$ & $0.49 \pm 0.04$ \\
Kenaf & 2.23 & $69.2 \pm 2.8$ & $18.1 \pm 0.9$ & $0.54 \pm 0.07$ \\
Evening prim rose & 1.80 & $77.4 \pm 0.6$ & $21.4 \pm 1.2$ & $0.50 \pm 0.05$ \\
Copy paper & - & $60.1 \pm 1.1$ & $7.7 \pm 0.6$ & $0.76 \pm 0.10$ \\
Kraft pulp paper & - & $39 \sim 132$ & - & - \\
\hline
\end{tabular}

time and diameter of the obtained products. The highest and lowest WDM times are identified in Japanese poplar (3.30 $\mathrm{min} / \mathrm{g})$ and evening prim rose $(1.80 \mathrm{~min} / \mathrm{g})$ respectively. Power consumption during WDM in woody bioresources was higher than in herbaceous bioresources. The filtration time appeared longest, at 74.5 min, in evening prim rose. The diameter of more than 50 individual microfibrillated products were measured and then calculated to determine the average value. Microfibrillated products from herbaceous bioresources showed more slender fibers than in woody bioresources. In particular, the smallest fibers were obtained from evening prim rose, even though they had a shorter WDM time than other species. The obtained size of approximately $20 \mathrm{~nm}$ is com- parable to a single elementary fibril, which can be obtained from herbaceous bioresources, even though the products were obtained without any pretreatment and include all hemicellulose and lignin (Eichhorn et al., 2010).

\subsection{Nanopaper obtained from microfibrillated products}

Table 3 shows the tensile properties of nanopaper prepared from microfibrillated products by WDM. Tensile properties of the nanopaper from herbaceous bioresources were higher than those of woody bioresources, in the whole range of WDM time investigated in this study. The highest tensile strength was found to be $77.4 \mathrm{MPa}$ in nanopaper from evening prim rose. Jang et al. (2012) reported on the tensile prop- 
erties of the microfibrillated product-derived nanopaper from hardwood and herbaceous bioresources. They reported that tensile strength was higher in nanopaper from herbaceous lignocellulose nanofibrils than in hardwood, even though grinding time was shorter. Stelte and Sanadi (2009) reported that the tensile strength of nanopaper from softwood was higher than that of hardwood, with the highest tensile strength reported at approximately $50 \mathrm{MPa}$. This tensile strength is lower than determined by our results. The elastic modulus was found to be in the range of 17-21 GPa in all samples, which was higher than that of copy paper. Sehaqui et al. (2010) also reported that the elastic modulus of nanopaper from softwood sulphite pulp was $13.4 \mathrm{GPa}$, which is lower than determined by our results. The elongation at break in all samples was less than $0.8 \%$.

\section{CONCLUSION}

The objective of this study is to investigate the micro- and nanoscopic morphological changes of eight different bioresources by utilizing different milling systems, and to compare the properties of nanopapers from microfibrillated products from various bioresources. The morphological characteristics of ground products are different in different milling systems. Mechanical grinding in herbaceous bioresources was more effective than in woody bioresources, with lower energy consumption, demonstrating the finer morphology. The tensile properties of nanopaper from microfibrillated products were better than those of copy paper, despite them containing all lignocellulosic components.

\section{ACKNOWLEDGEMENT}

This study was supported by the National Research Foundation of Korea (NRF) grant funded by the Korea Government (MSIP) (NRF-2016R1C1B1008909). This study was supported by the Research Fellowship Program of the National Institute of Forest Science (NIFoS) in 2017.

\section{REFERENCES}

Alila, S., Besbes, I., Vilar, M.R., Mutjé, P., Boufi, S. 2013. Non-woody plants as raw materials for production of microfibrillated cellulose (MFC): A comparative study. Industrial Crops and Products 41: $250 \sim 259$.

Chakraborty, A., Sain, M., Kortschot, M. 2005. Cellulose micriofibrils: a novel method of preparation using high shear refining and cryocrushing. Holzforschung 59: 102 107.

Eichhorn, S.J., Dufresne, A., Aranguren, M., Marcovich, N.E., Capadona, J.R., Rowan, S.J., Weder, C., Thielemans, W., Roman, M., Renneckar, S., Gindl, W., Veigel, S., Keckes, J., Yano, H., Abe, K., Nogi, M., Nakagaito, N., Mangalam, A., Simonsen, J., Benight, A.S., Bismarck, A., Berglund, L.A., Peijs, T. 2010. Review: Current international research into cellulose nanofibers and nanocomposites. Journal of Materials Science 45: 1 33.

Fengel, D., Wegener, G. 1983. Wood : chemistry, ultrastructure, reaction. Walter de Gruyter \& Co. Berlin, Germany.

Jang, J.-H., Kwon, G.-J., Kim, J.-H., Kwon, S.-M., 
Changes of Micro- and Nanoscopic Morphology of Various Bioresources by Different Milling Systems

Yoon, S.-L., Kim, N.-H. 2012. Preparation of cellulose nanofibers from domestic plantation resources. Journal of the Korean Wood Science and Technology 40(3): 156 163.

Jang, J.-H., Lee, S.-H., Endo, T., Kim, N.-H. 2013. Characteristics of microfibrillated cellulosic fibers and paper sheets from Korean white pine. Wood Science and Technology 47: 925 937.

Jonoobi, M., Harun, J., Shakeri, A., Misra, M., Oksman, K. 2009. Chemical composition, crystallinity, and thermal degradation of bleached and unbleached Kenaf bast (Hibiscus cannabinus) pulp and nanofibers. BioResources 4(2): $626 \sim 639$.

Kalia, S., Dufresne, A., Cherian, B.M., Kaith, B.S., Avérous, L., Njuguna, J., Nassiopoulos, E. 2011. Cellulose-based bio- and nanocomposites: A review. Journal of Polymer Science 2011: 1 35.

Kondo, T. 2005. Nano-pulverization of native cellulose fibers by counter collision in water. Cellulose Communications 12(4): 189 192.

Lavoine, N., Desloges, I., Dufresne, A., Bras, J.
2012. Microfibrillated cellulose - Its barrier properties and applications in cellulosic materials : A review. Carbohydrate Polymers 90: 735 764 . Sehaqui, H., Liu, A., Zhou, Q., Berglund, L.A. 2010. Fast preparation procedure for large, flat cellulose and cellulose/inorganic nanopaper structures. Biomacromolecules 11: 2195 2198.

Siró, I., Plackett, D. 2010. Microfibrillated cellulose and new nanocomposite materials: a review. Cellulose 17: 459 494.

Stelte, W., Sanadi, A.R. 2009. Preparation and characterization of cellulose nanofibers from two commercial hardwoodand softwood pulps. Industrial \& Engineering Chemistry Research 48: $11211 \sim 11219$.

Taniguchi, T., Okamura, K. 1998. New films produced from microfibrillated natural fibers. Polymer International 47: 291 294.

Yano, H., Sugiyama, J., Nakagaito, A.N. 2005. Optically transparent composites reinforced with networks of bacterial nanofibers. Advanced Materials 17(2): 153 155. 